\title{
MANAGEMENT OF POSTGRADUATE EDUCATION IN GENERAL MEDICINE AT THE MEDICAL UNIVERSITY OF PLOVDIV
}

\author{
Petrova G., R. Assenova ${ }^{1}$, G. Foreva ${ }^{1}$, V. Madjova $^{2}$ \\ Section Medical pedagogy, Public Health Faculty, Plovdiv Medical University, \\ ${ }^{1}$ Section General Practice, Public Health Faculty, Plovdiv Medical University, \\ ${ }^{2}$ Department of Family Medicine, Varna Medical University
}

Reviewed by: assoc. prof. St. Popova

\begin{abstract}
The changes in the health care system came along with the more establishing concept of permanent education. Management of the education is crucial for training's quality promotion and professional adaptation of general practitioners (GPs). MATERIALS AND METHODS: The sociological research is in the form of an anonymous questionnaire. It comprises 79 (seventy-nine) GPs who have completed the specialization training. RESULTS AND DISCUSSIONS: The men quota and those of women are equal. The average age is $41.12 \pm 6.67$ and the average medical length of employment is $13.32 \pm 7.21$ years. The predominant part of respondents have no specialty $(64.56 \pm 5.38 \%)$, and those who already have one specialty, are specialists in internal medicine or pediatrics. The assessment for the overall organization of learning process - mostly, and it is very good $(39.24 \pm 5.49 \%)$ and good $(34.18 \pm 5.34 \%)$. CONCLUSION: Interns are not satisfied with the ratio theoretical/practical training. Keeping the same duration and increasing its efficiency could be the expected change.
\end{abstract}

Key words: postgraduate education, general practitioner

\section{INTRODUCTION}

The changes in the health care system in Bulgaria for the past ten years came along with the more and more establishing concept of permanent education or lifelong learning. Nowadays adult education is considered in the context of the permanent education concept. Presently adult education is necessity which can be satisfied in various ways, by different means, where different results are achieved (5). Lifelong learning comprises all result-oriented activities, both formal and informal, realized throughout life aiming at improving knowledge, skills and competences (6).

Launched in 2000 health care reform in out-of-hospital care placed many challenges before the five medical universities in the country. Curriculum and postgraduate programs have been introduced to the general practitioners (GPs) referring the promotion of qualification of those who wish to practice individually as a family doctors. Their training must be carried out at medical universities with temporary discontinuing work and for the period of three years. It is organized in two directions: theoretical, by lecturers having academic rank,

Address for correspondence:

G. Petrova, Section Medical pedagogy, Public Health Faculty,

Plovdiv Medical University, 15A V. Aprilov, str.

Bulgaria, Plovdiv 4002

e-mail: gkpg21@yahoo.com and practical, in the form of modules in clinics under the guidance of assistants (tutors). Post-graduate education with the GPs shall finish with theoretical and practical examination before a state examination committee.

All the above put an emphasis on the continuous medical education as a must in maintaining and promoting GPs qualification in Bulgaria. Its organization and management is crucial for training's quality promotion, professional adaptation and realization of general practitioners in Bulgaria.

The present elaboration aims at examining the entire organization, conducting and management of the postgraduate education in General Medicine at the MU - Plovdiv.

\section{MATERIALS AND METHODS}

The sociological research is in the form of an anonymous direct group interview. It comprises 79 (seventy-nine) general practitioners who have completed the three-year specialization training in General Medicine prior to their state examination at the MU - Plovdiv. The research was conducted in 2007/2008 academic year through a form of 28 questions, distributed in the following modules: educational technologies, practical training, control and assessment system, motivation for learning and attitude towards lecturers. The source sociological information collected has been processed through the SPSS v. 15.0 software package. 


\section{RESULTS AND DISCUSSIONS}

The analysis of results shows that the men quota $(44.30 \% \pm 8,88 \%)$ and those of women $(55.70 \% \pm 8,88 \%))$ are almost equal. The average age of research quota is $41.12 \pm 6.67$ and the average medical length of employment is $13.32 \pm 7.21$ years. The predominant part of respondents have no specialty $(64.56 \pm 5.38 \%)$, and those who already have one specialty, are specialists mostly in internal medicine or pediatrics.

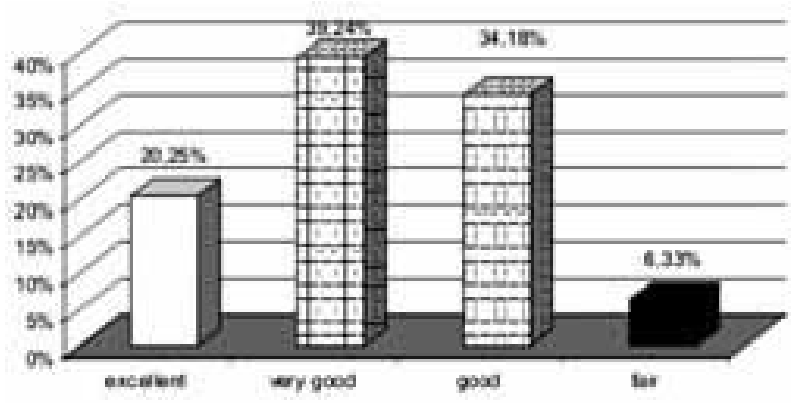

Diagram 1. Assessment for learning process organization in General Medicine

Students' assessment of teaching quality is a relatively new category and practice. It is a complex pedagogical phenomenon, determined by many and various factors; its work affect different objects and processes; it can be interpreted in different contexts, etc., and in any case it is considered as a useful feedback in the process of academic education. The present experience in applying students' assessment as a part of and in the context of educational quality assuring systems shows that its validity and reliability are no longer under discussions today rather than finding paths for its complete utilization (2). With this relation, we have asked for the opinion of those included in our research regarding their assessment for the overall organization of learning process - mostly, and it is very good $(39.24 \pm 5.49 \%)$ and good (34.18 $\pm 5.34 \%)$ (Diagram 1). The results received satisfy us to a considerable degree.

It may be noted that the post-graduate education provided in such a way do not satisfy interns $(64.56 \pm 5.38 \%)$, they are not satisfied with the ratio theoretical/practical training. At this stage the ratio theoretical/practical training is $70 / 30$. It would be appropriate this ratio changed in the future in favor of practical training. Increasing practical training on the account of the theoretical one would increase the sense of achievement from the postgraduate education. Satisfaction with education is one of the factors for increasing its efficiency, thus, this educational quality element shall be a subject matter of future scientific and practical elaborations and researches.

Interns' learning assessment as a whole correlates with their practical training assessment. In this case, too, respondents find that the practical training is organized in a very good level $(35.90 \pm 5.43 \%)$ and good (23.08 $\pm 4.77 \%)$ level. Keeping the same duration and increasing its efficiency could be a possible change when conducting practical training, according to interns. $(63.64 \pm 5.48 \%)$ of respondents express the above opinion. A key figure in conducting practical training is one of the assistant in the clinics - a tutor. According to $(53.25 \pm 5.96 \%)$ of respondents both parties benefit from such a type of education due to the daily work, of both trainers and learners, with patients. It seems that interns' idea of contemporary education coincides only with that regarding the education in General Medicine, Internal Medicine, Pediatrics and Neurology to a certain extent (Table 1). It is only $1 / 3$ of all subjects studied during the three-year course of studies.

The application of modern educational technologies could be a possible instrument for increasing knowledge interest and activity among learners. At this stage regarding the said modules,

Table1. Interns' idea of contemporary education, per modules

\begin{tabular}{||l|c|c|c|c|c|c||}
\hline \hline Module & Number & Yes \% & Sp & Number & No \% & Sp \\
\hline 1. General Medicine & 52 & 65.82 & 5.34 & 27 & 34.18 & 5.34 \\
\hline 2. Internal Medicine & 35 & 44.30 & 5.59 & 44 & 55.70 & 5.59 \\
\hline 3. Childhood Diseases & 32 & 40.15 & 5.52 & 47 & 59.49 & 5.52 \\
\hline 4. Surgery, Orthopedics and Urology & 12 & 15.19 & 4.04 & 67 & 84.81 & 4.04 \\
\hline 5. Eye Diseases & 30 & 37.97 & 5.46 & 49 & 62.03 & 5.46 \\
\hline 6. Ear, Nose and Throat & 10 & 12.66 & 3.74 & 69 & 87.34 & 3.74 \\
\hline 7. Cutaneous Diseases & 15 & 18.99 & 4.41 & 64 & 81.01 & 4.41 \\
\hline 8. Infection Diseases, Hygiene and Epidemiology & 18 & 22.78 & 4.72 & 61 & 77.22 & 4.72 \\
\hline 9. Psychiatry & 23 & 29.11 & 5.11 & 56 & 70.89 & 5.11 \\
\hline 10. Phthisiatry & 5 & 6.33 & 2.74 & 74 & 93.67 & 2.74 \\
\hline 11. Obstetrics and Gynecology & 29 & 36.71 & 5.42 & 50 & 63.29 & 5.42 \\
\hline 12. Neurology & 33 & 41.77 & 5.55 & 46 & 58.23 & 5.55 \\
\hline \hline
\end{tabular}


which do not correspond with the idea of contemporary education, interns' training is conducted in a way, not very different from that with the medical students at the MU - Plovdiv. According to K. Madjirova (1997) education management orientation towards innovations aims at modem education, education of good quality, one of the leading forces in society and at the same time - adapted to the social and economic changes (3). With that respect, the post-graduate education in General Medicine should promote but repeat the academic education in Medicine. In the organization of learning process with adults it is focused on the process of acquiring knowledge and skills (typical of the andragogical approach) rather than on the educative content (typical of the pedagogical approach). Basically, it is assumed that there are many other sources of knowledge and information besides the teachers: people, media, educational (and non-educational) materials, different types of experience (1). Andragogy has been developing more and more thoroughly during the past years which lead to a continuous enlargement, improvement and extension of its problems (4).

\section{CONCLUSION}

Our research is related to the learning process organization, its importance for increasing training efficiency and quality at the higher institutions of learning, i.e., the andragogical issues in the context of higher education pedagogy allow us to draw the following significant conclusions:

- There are very good results regarding interns' assessment for the overall learning process organization

- Interns are not satisfied with the ratio theoretical/practical training in the different subjects
- Keeping the same duration and increasing its efficiency could be the expected change when conducting practical training, according to interns

- A key figure in conducting the practical training is one of the assistant in the clinics - a tutor. According to respondents such a type of education is considered partnership where both trainers and learners benefit from

- Interns' idea of contemporary education coincides only with that regarding the education in General Medicine, Internal Medicine, Pediatrics and Neurology to a certain extent. It is only $1 / 3$ of all subjects studied during the three-year course of studies.

\section{REFERENCE}

1. Gyurova V. (2005) Teaching adults. Pedagogy, 2nd part: Theory of the education. Didactics, Ed. T. Popov, Sofia, Tipographica Ltd, 526 p.

2. Ilieva M. (2002) Students' assessment of the teaching, Sofia HTMU, 174 p.

3. Madjurova K. (1997) New approach in management in education - state, tendency and prognosis Strategies in educational and scientific politics 4:85-91

4. Petrov P., Atanasova M. (2003) Education for adults Sofia, Veda Slovena-JG, p.256

5. Totzeva Ya. (2001)Problems in teaching adults, Sofia, Daniela Ubenova, p.167.

6. Yzakova J., Georgieva A. (2002) Life long learning - definition, dimension, strategy, Sofia, Gea, $203 p$. 